\title{
LEY Y DEMOCRACIA EN LA ERA DEL TERRORISMO
}

\author{
Maximiliano E. Korstanje \\ Universidad de Palermo, Argentina
}

http://dx.doi.org/10.5209/rev_NOMA.2012.v35.n3.42201

Resumen.- Progresivamente el orden estatal modifica la ley acorde a sus propios intereses. Creíamos haberlo visto todo luego de las infames leyes de Nuremberg, pero no fue así, incluso Estados Unidos mismos promulgaba en sus discursos la democracia, mientras en su seno defendía la segregación a la comunidad afro. Estamos de acuerdo en que la ley se encuentra sujeta a la economía, pero existen circunstancias donde el derecho se transforma en pre-requisito de un orden anti-democrático. Si la antigua forma democrática griega advenía por la posibilidad ciudadana de derogar leyes, si éstas eran consideradas injustas, la anglo-democracia (funcional al capitalismo) hoy recicla estados y territorios completos instalando regimenes en donde no existe diálogo entre gobernantes y gobernados. Esa brecha es llenada por el capital que desdibuja la relación política hasta convertirse en una dictadura.

Palabras clave.- ley, poder, política, bienestar, dictadura, terrorismo

Abstract.- Gradually, the law and state are funcional to defend the interest of status quo. We believed having seen anything before the disaster of Nuremberg, but we were wrong. Even United State defended racism inner-ward at time this power expanded the discourse of democracy beyond its boundaries. We strongly believe not only that the law is determined by economy but also the right paves the way for the upsurge of dictatorship. Whether the old democracy in Greece encouraged the possibility to derogate an unfair law if necessary, the Anglo democracy (functional to capitalism) today recycles sites and states in order to install a regime of consumption where the gap between representants and citizens are shortened. As a result of this, the capital plays a pivotal role in configuring the tenets of dictatorship beyond its veil of liberty.

Keywords.- law, power, politics, well-being, dictatorship, terrorism

\section{Introducción}

La discusión sobre la distribución de derechos parece amplia y profunda. Los académicos no dejan de preguntarse sobre los alcances y limitaciones de la ley en cuestiones típicamente morales. En Argentina, el último caso mediático apuntaba a un joven (Pablo) baleado en un asalto que se negaba a recibir una transfusión ya que su religión (testigos de Jehová) expresamente se lo prohibía. Las tres cámaras y la Corte Suprema argentina fallaron a favor del damnificado arguyendo que si el orden social no estaba en juego, la ley no podía presionar a un sujeto para recibir una transfusión, contra su voluntad. Particularmente, este hecho marca los límites de la libertad política y hasta que punto el Estado debe dejar morir a un ciudadano si éste lo desea. ¿Es la creencia en una condenación eterna superior como valor a la vida misma?. Particularmente una de las cuestiones más representativas de las Ciencias sociales y jurídicas es la posición de la norma en la vida social de los hombres, su vínculo con el sistema de creencias y los procesos productivos. Este breve ensayo tiene como función examinar hasta que punto la democracia y organización republicana se ha transformado en una verdadera fuerza de 
emancipación, como muchos piensan, y no en todo lo contrario. Existen diversos ejemplos en todo el mundo de cómo la ley se conforma por grupos establecidos en el poder que sólo cuidan sus intereses. Nuestra tesis es que la Anglo-democracia, neologismo usado para explicar como funciona la democracia anglo-americana es funcional no solo a la expansión capitalista sino además a todos los procesos evolutivos por el cual el hombre se ha convertido en un mero producto de consumo, fiel a su imagen y circunscripto a su poder de compra. El dinero no sólo ha alterado las instituciones políticas sino que ha creado una brecha entre representantes y representados, desdibujando las fronteras entre la ley y la moral. La ley promulgada por las Anglo-democracias no conoce de reparos éticos, mucho menos se preocupa por las personas. Pensábamos haber aprendido la lección después de Nuremberg y las leyes nazis de segregación racial, pero ¿puede un país considerado la cuna de la democracia llevar a cabo invasiones unilaterales sin consenso internacional, vulnerando los mismos principios de la democracia?, ¿es la ley misma la precondición para el advenimiento de una dictadura?.

\section{Debate Conceptual}

Para responder a esta pregunta debemos considerar la discusión entre dos jurístas que de alguna forma marcaron a fuego el siglo XX, Hans Kelsen y Carl Schmitt. Para el primero, la norma positiva siempre debía quedar ajena a la voluntad de los hombres buscando, de esa forma, el bien común mientras para el segundo, toda norma o ley no podía ser sostenida sin la legitimidad del más fuerte y por ende a la naturaleza de la decisión política. La discusión resume que aun cuando (las leyes de Nuremberg de separación racial) hayan sido legales, pueden no ser éticas. La tesis del decisionismo político que ha inspirado tanto terror en algunos estudiosos, obliga a repensar cuales son los limites éticos de toda ley. La función de los tribunales y la representatividad de los legisladores en cuanto a los intereses del pueblo. La base de la interpretación ciertamente es subjetiva, sólo que su formalización puede no serlo.

Respecto a la interpretación de la jurisprudencia Gary Minda (1995) observa que en Estados Unidos se han dado dos movimientos igualmente influyentes en lo que se refiere a la aplicación doctrinaria de la ley. Los formalistas y los instrumentalistas perseguían objetivos diferentes en los orígenes del debate sobre los alcances del derecho; para los primeros la ley debía ser una cuestión formal objetiva ajena a las voluntades humanas o al contexto social. Por el contrario, para la segunda camada, la ley estaba socialmente construida y consensuada por medio de la experiencia personal. Hablar de la ley en abstracto no solo sería un grave error sino un obstáculo para la interpretación de los jueces. De estas dos tendencias antagónicas, si se quiere, nacería el derecho moderno estadounidense donde se prima la objetividad de la ley teniendo en cuenta las particularidades y necesidades de la población local para modificarla (si es necesario). Dicha combinación contemplaba la posibilidad de imprevistos y abogaba además por la eficiencia de la misma jurisprudencia para salvar los baches producidos por su propia aplicación. En base a esta argumentación, entonces la ley era concebida como una forma de distribución de riesgos aceptables que armonizaban la vida en sociedad con el fin de minimizar las potenciales pérdidas.

\section{El discurso de La Ley}

Respecto al dilema sobre si la interpretación de la ley debe gravitar en mayor proporción que la ley misma, Sunstein considera que la aplicación del caso es más importante 
porque se somete al escrutinio de los detalles que sólo son propios de ese caso. Si bien el poder de la ley no debe ser ignorado, como así tampoco su contenido, la jurisprudencia debe basarse en un razonamiento legal práctico cuyo capital se acumule con el tiempo. A medida que determinado problema haya sido abordado por más juzgados, mayor será la posibilidad de llegar a una resolución justa y equilibrada para todos los involucrados. Sunstein, en este punto, reconoce que la sentencia debe ser comprendida como una mediación en donde todos los actores deben relegar parte de su demanda, pero en ese proceso, la decisión del juez queda sujeta al bien general de los involucrados. La jurisprudencia tiene como función social reducir no solo el riesgo generado por el sistema mismo, sino la ambigüedad de las prácticas sociales. La ley puede ser tan circunstancial como la política. Cuando eso sucede existe una disociación entre el contenido de una ley y su aplicación. Por ejemplo, se puede prohibir a los automóviles circular a más de 70 kilómetros por hora, pero no a un auto policial en persecución de un criminal. La resolución de la paradoja que trae consigo la aplicación normativa no solo lleva al instrumentalismo, sino que apela al principio de "excepción" de la norma. Los estados de emergencia, como guerras o desastres evocan ese principio de excepción para la no aplicación de la ley (Sunstein, 1996). Entonces, si seguimos el razonamiento jurídico instrumentalista debemos admitir que la "invención de diversas crisis" puede llevar a una anomia auto-inducida. La emergencia pospone la fuerza normativa de tal forma que modifica la forma de interpretarla.

Siguiendo este argumento, Sunstein (1996: 61) explica que la vocación democrática de un país y su apego a la ley convergen en un estado incompleto de la teoría jurídica que debe ser aplicada en un fallo. Cada caso debe ser sustentado por medio de una lógica jurídica que permita reducir el conflicto político. La controversia que se mueve de un lado a otro de la arena política, pero existen situaciones en donde se da una laguna jurídica (falta de normativa). Gracias a esta carencia, la jurisprudencia puede avanzar sellando la grieta con una nueva normativa. Por lo tanto, en cada fallo se sacrifican pequeñas libertades en pos de un bien mayor donde primera la seguridad de todos los ciudadanos. La ley se encuentra todo el tiempo legislando sobre cuestiones que hacen a los accidentes 0 a problemas no contemplados anteriormente. Aquello que la ley, precisamente, debe restringirse es la capacidad de actuar en el futuro (preventiva) antes de que el hecho se consume.

En perspectiva, R. Dworking (1996) plantea un tema por demás interesante respecto a la unidad territorial y a los conflictos entre poderes dentro de la democracia. En primer lugar ¿porque debemos acatar el orden constitucional de una nación cuando no estamos de acuerdo?. Segundo, ¿cuál es el sentido de la representación política?. El jurisperito americano explica que existen dos tendencias dentro de las Ciencias Jurídicas que explican el problema. Existe una corriente que se apoya en la interpretación moral de la constitución lo cual apela a la intervención de los jueces como garantes del orden legal. No obstante, surge un problema ya que la constitución y su lectura moral pueden bajo ciertos contextos convertirse en criterios de evaluación poco claros, abstractos que llevan a formar una aristocracia que atentan contra la democracia, si la definimos como "el gobierno de todos". Una segunda corriente, entonces, sostendrá que el orden societal se mantiene gracias a la premisa de la mayoría y la idea de representación parlamentaria. Desde esta perspectiva, los asuntos que atañen a la comunidad deben ser tratados por el poder político y no por los jueces. Plantea Dworking, que incluso la gobernabilidad de una sociedad puede estar en peligro cuando se evoca en cuestiones políticas situaciones que fuese definidas en otras épocas. La constitución, a tal punto, no garantiza ni la libertad ni la correcta administración de un país. 
Para C. Sunstein (1997), el andamiaje jurídico sobre el cual descansa la nación es la constitución, no obstante a ello, la carta magna es ambigua y no puede dar detalles sobre los casos a legislar cuando se ha escrito cientos de años atrás. Como resultado, la supuesta imparcialidad de la Justicia en interpretar la constitución se sucede de una visión sesgada y funcional a las aristocracias gobernantes. En efecto, el poder judicial lejos de proteger a los ciudadanos, admite Sunstein, vela por los intereses de los grupos privilegiados. Cuando en Estados Unidos, la corte Suprema tuvo que intervenir en cuestiones de racismo o discriminación hacia ciudadanos negros por parte de algunos estados, lo hizo en forma fría legitimando implícitamente la exclusión. En estos casos, la Corte esgrimió que si bien se debe reconocer la igualdad de todos los hombres frente a la ley, es facultad de cada estado legislar para sí mismo sus hábitos y formas de organización económicas. Siendo el racismo una cuestión cultural e histórica y no legal, la Corte falló argumentando que la constitución debe permitir que cada Estado de la unión organice sus propias formas de producción asignando ciertos derechos a unos y quitándoles esos mismos derechos a otros. Mismas aplicaciones a favor del andamiaje económico se han observado en los fallos vinculados a los horarios mínimos de trabajo, derecho de comercio entre estados o reivindicaciones salariales. En cualquier caso, el poder judicial es un garante del orden económico vigente similar a otros poderes como el ejecutivo o el legislativo. La ley puede tanto incluir como excluir. La diferencia entre una $u$ otra postura radica en como la ley rodea al hábito social, si lo considera pre-político y sólo se remite a contornearlo, o si la ley misma crea la costumbre lo cual implica un sentido de intervención. Cuando una persona es condicionada por religión, raza, género o poder adquisitivo entre otras cuestiones, la concepción que se aplica es la segunda.

A nuestro entender el gran vulnerador moral de las aplicaciones jurídicas, no es el poder judicial mismo como piensan Sunstein y Dworking, sino la forma en que se construye y se negocia la democracia. Por regla general se nos enseña, incluso en la universidad, que la democracia es la mejor forma organizativa y representativa que conocemos. Incluso, que la libertad y sólo ella puede proteger los intereses de todos. A diferencia de la dictadura que somete a los ciudadanos a la ley de uno sólo, la democracia es debate y conflicto. Esta posición ampliamente extendida en nuestra era moderna no solo es falsa, sino que además a una dictadura en sí misma. La pregunta debe formularse de la siguiente forma, ¿por qué los griegos padres inclaudicables de la democracia defendía también la esclavitud y la monarquía?, ¿no es ello una profunda contradicción?.

\section{La Democracia}

Uno de los pensadores contemporáneos que mejor ha explicado la diferencia entre la democracia moderna y la griega ha sido C. Castoriadis. Según su postura, la democracia poco tiene que ver con la organización política republicana que rigen los estados modernos. Los padres fundadores de la democracia, es decir, el pueblo griego utilizaba a la misma como un recurso para abolir una ley si ésta era considerada injusta. La democracia no estaba vinculada ni a la organización política, autoridad del rey, ni mucho menos a la libertad, ya que la esclavitud en el mundo antiguo no solo era moneda corriente sino un mecanismo de reproducción económico-social importante. Los griegos se habían dado cuenta que si todos tienen derecho a todo, entonces nadie tiene derecho a nada. Esta premisa adquiere un rol fundamental en el pensamiento helénico ya que por un lado legitima la monarquía mientras por el otro construye un puente entre el mundo político y el religioso. A diferencia de la mitología judeo-cristiana donde el universo está a los pies de la humanidad, la cosmovisión greco-latina considera que los hombres son sólo una parte minúscula del mundo sin derecho natural a su administración. Para el 
pensamiento helénico los hombres vienen al mundo para coexistir con otras criaturas, y su derecho a administrar el mundo está determinado por lo que el hombre puede hacer o demostrar. En consecuencia, las estructuras mitológicas del mundo griego, donde primero nace la democracia, fagocitan la demostración de habilidades, fuerzas y competencias. El hombre debe demostrar ser merecedor de la gracia divina. Si la mitología cristiana y semítica se hace patriarcal, la griega hace de sus dioses simples consejeros de los hombres, cuyas enseñanzas pueden seguirse o rechazarse. Artífice de su propio destino, el ciudadano griego no cuestiona la desigualdad, ni el hambre, ni la muerte, las acepta como parte de su condición primera (Castoriadis, 2006).

En la actualidad, por el contrario, las democracias no solo distan de conferirles a sus ciudadanos el poder de veto, sino que además introduce a la libertad como un mecanismo que facilita la movilidad laboral. Podemos hablar entonces de una "anglo-democracia" donde los valores culturales predominantes son el trabajo rentado, la movilidad laboral, el riesgo, el capital y la organización republicana. Es, precisamente, sobre este último concepto que se crea una brecha entre gobernados y gobernantes, representados y representantes. Los primeros confieren autoridad a sus gobiernos en forma temporal, por períodos renovables (a diferencia del mundo griego donde la autoridad del rey era transmisible y duraba toda la vida), pero durante ese lapso se les niega la posibilidad de modificar las leyes en forma directa. Sólo los representates legislativos y ejecutivos tiene la posibilidad de crear la ley, aun cuando ésta se injusta, o atente contra algún derecho básico. Se da en "la anglo-democracia", como resultado, una dictadura donde el capital llena el vacío que deja el sistema republicano. La necesidad de liberación, propia de la modernidad, se corresponde con pautas abiertas de consumo en donde el ciudadano puede vender su fuerza de trabajo al empleador con mayor capital. ¿Cómo hace el capital para modificar o vaciar la significación de las instituciones sociales?, o lo que es peor, ¿Cómo un país democrático puede unilateralmente emprender una guerra preventiva?.

\section{La Política en la era Posmoderna}

Dos de los autores que pueden responder a este dilema son M Hardt, A Negri y D. Harvey. Para éste último, una de las cuestiones más importantes sobre el término es poder llegar a una definición clara y objetiva sobre la modernidad. Existen no solo diferentes acepciones de modernidad y posmodernidad, sino que además lo posmoderno parece diluirse en un cambio anárquico y progresivo.

Desde su perspectiva, Harvey considera que la posmodernidad, en tanto, vanguardia estética, ha roto con los ideales de la ilustración sobre lo eterno y lo inmutable para convertirse en "un pastiche" que se mueve bajo una lógica de "destrucción creativa". Para crear nuevas cosas, lo postmoderno avanza destruyendo todo a su paso. Pero a su vez, vuelve a destruir lo que había creado retroalimentando un proceso de destrucción, construcción para una nueva destrucción (ambivalencia). Por otro lado, si la llustración propugnaba la idea que el mundo podía ser descrito y controlado sólo sí los hombres aceptaban que todo problema tenía una univoca causa, para la posmodernidad los problemas son multi-causales y su etiología totalmente subjetiva.

Ciertamente, el cambio pudo haberse producido, admite Harvey, por el malestar que había provocado la llustración y una pérdida de fe "progresiva" en el avance del progreso. La desigualdad de las clases sociales, asimismo, producidas por el avance del capitalismo fue otro factor de quiebre epistémico que asumía la idea que las cuestiones del hombre requerían múltiples respuestas, nace así una especie de relativismo que reemplaza al 
argumento científico de la Escuela de Viena por una "hegemonía" de las cualidades sensibles del sujeto para comprender la realidad. En consecuencia, no habría un "mundo real" sino varios mundos construidos y presentados como "reales". Se da, en resumen, progresivamente una serie de quiebres y fragmentaciones de saberes que conllevan a una confusión metodológica subordinada a una lógica de consumo capitalista y a una vida social basada en el cálculo racional de los efectos (especulación). Esa incesante incertidumbre e inestabilidad sentaron las bases para el advenimiento de un miedo constante el cual puede observarse en todos los aspectos importantes de la vida en sociedad. Cabe aclarar que el primer modernismo, hasta 1945, fue "heroico" pero atravesado por el "desastre".

Consecuente a ese proceso, sobrevino un "modernismo alto" en donde se enfatizaban los valores del progreso y la emancipación de la llustración; pero la racionalidad del altomodernismo dio lugar a una nueva forma estética, el posmodernismo; movimiento por el cual la alineación del hombre-maquina promovida por ciertos sectores artísticos y culturales fue absorbida, elaborada y canalizada por los grupos políticos en una ideología liberal específica. Para tal caso, escribe Harvey, los políticos comienzan a incorporar nociones estéticas creando una ideología oficial que hace de la rebelión no solo su mayor valuarte, sino un fin en sí. La burocracia técnica dio lugar a movimientos anti-modernistas (principios del 60), que generaron una fragmentación de la cultura en varias contraculturas. Si bien todos estos movimientos, terminaron en un estrepitoso fracaso fueron la precondición para el surgimiento de la postmodernidad y toda la "incoherencia" que trae consigo.

En este punto y para Harvey, el posmodernismo alcanza también una idea de fragmentación pero sin intentar contrarrestarla como sí lo intentaba el modernismo. El posmodernismo parte de varias narrativas todas ellas consumidas dependiendo del contexto del sujeto, sin un lugar de poder fijo sino simplemente transmutable. Si una de las características fundamentales de la modernidad es hablar por los otros pero bajo un único argumento, la posmodernidad enfatizará en que todas las minorías tienen su propio derecho a expresarse y a ser aceptados (concepción pluralista). Los textos narrativos de los actores serían complejos textos y voces que anteceden y destruyen la posibilidad de instaurar cualquier meta-narrativa. Básicamente, el posmodernismo quiere perfilarse como una forma de experimentar y estar en el mundo pero su fragmentación conlleva a un problema psicológico el cual no ha sido observado en otras épocas, el riesgo, la ambigüedad y la incertidumbre.

La ruptura entre la posmodernidad con la modernidad nace de la crisis Árabe-Israelí en 1973 que puso en vilo a todo el mundo Occidental por el embargo a las exportaciones de petróleo. Como resultado de un aumento en las fuentes energéticas, el capital existente tuvo que diversificarse hacia el préstamo y una posterior acumulación flexible. De esta forma, las nuevas económicas de mercado hicieron un fuerte énfasis en el signo como criterio de consumo principal. Si la lógica fordista de montaje exigía a los fabricantes tiradas de productos seriadas, la nueva forma económica se centró en el consumo a medida cuya reacción fue la creación de un capital global y móvil. Los constantes cambios que exige el capital móvil obligan a los consumidores no solo a vivir el día a día sino además a verse envueltos en un clima de constante incertidumbre donde la antigua compresión del espacio-tiempo se ha desdibujado por completo. La ilustración y la crisis de valores que ella despertó obligaron a mirar el mundo por medio de un nuevo prisma, los mapas. De esta manera las crisis subsiguientes del modernismo y posmodernismo empujaron a una nueva concepción de espacio y tiempo. La paradoja central de la posmodernidad, sin lugar a dudas, es cuanto menores son las barreras espaciales para la 
movilidad individual, mayor es la sensibilidad del capital a los cambios. En consecuencia, el incentivo para reciclar y diferenciar los lugares para atraer flujos de capital es un fenómeno más que interesante para investigar. Existe, adhiere Harvey, una tensión entre centralizar y descentralizar, entre historia y presente, son aspectos importantes para comprender la competencia por la hiper-acumulación; sin más, la tendencia a la patrimonialización de la cultura o a la invención de espacios para el consumo turístico son ejemplos claros de dicho proceso (Harvey, 2004).

\section{El Nacimiento de la Bio-política}

Multitud ha de ser un libro no solo ampliamente recomendado para especialistas en temas de riesgo y terrorismo, sino en cuestiones de bio-política en general. La posición inicial de esta profunda investigación intenta ser una lectura holística de comprensión respecto al problema de la modernidad capitalista, y su impacto sobre la ley. ¿Está la ley moderna a favor del consumo capitalista?.

La modernidad ha implicado un cambio, el cual puede ser interpretado como amenazante o simplemente una oportunidad para saltar a un estado más democrático en donde los actores y sus subjetividades se combinen. Una de las particularidades que distingue a estos dos pensadores del resto, es la visión del rol de la bio-política como mecanismo de adoctrinamiento orientado a crear comunidad. En ese contexto, la multitud debe ser considerada como un producto residual del capitalismo y de la excesiva movilidad de las fuerzas productivas. A lo largo de su valioso aporte, M. Hardt y A. Negri explican que la guerra obedece a factores técnicos donde priman cuestiones organizativas que trascienden al acto de guerra mismo. En sí, la guerra puede definirse como un proceso temporal y extraordinario que subvierte las fuerzas productivas de una comunidad, alterando de esa forma la vida social en su conjunto. Es de común interés notar que en los últimos tiempos los estados bélicos se han transformado en mecanismos bio-políticos generadores de legitimidad política para el Imperio. La lógica jerárquica que ha caracterizado la vida social ha dado lugar a nuevas formas descentralizadas (redes) de trabajo, consumo y movilidad. Las sociedades pueden ser estudiadas por medio de como celebran la guerra. En la era del Imperio, las condiciones bio-políticas no solo generan subjetividades, sino nuevas formas de hacer la guerra donde el enemigo es parte de la misma sociedad y puede atacar en cualquier momento. Las formas clásicas que llevaban ejércitos enteros al campo de batalla y cuyas organizaciones estaban delineadas en forma precisa y vertical, han cambiado a redes en donde la figura del enemigo y del amigo se ha desdibujado. Los límites éticos y morales que llevan al estado a convivir con su propio enemigo, son hoy objeto de debate. Con la aparición de Guantánamo en Cuba, y la violación a los derechos humanos luego de las invasiones de Irak y Afganistán, los Estados Unidos vieron que el terrorismo se combate por medio de la imposición de redes militares. El antiguo código estamental del caballero, donde el civil quedaba a resguardo del conflicto, se ha transmutado. Ahora todos pueden ser víctimas del terrorismo en cualquier momento y en cualquier lugar. La bio-política iguala a los ciudadanos en tanto que material genético viable para la maquinaria de consumo. La democracia en el sentido griego más clásico ha muerto luego de la guerra del Peloponeso. La forma moderna de practicarla ha sentado las bases para la incorporación de los poderes económicos recluyendo al ciudadano al disfrute de la propiedad privada.

Particularmente, el terrorismo se corresponde como un producto de la posmodernidad que trasciende a las antiguas resistencias guerrilleras de la década del 70. Siguiendo este argumento, la gran producción de subjetividad permite la creación de multitudes unidas 
por "aquello que tienen en común", lo cual lleva a los hombres a una democracia real que desafía la lógica imperial. Sí, admiten Hardt y Negri, el capital necesita a la "multitud" para poder reproducirse, entonces se originan diversas resistencias. La lucha que hasta decenios antes era vertical, entre todos compactos, naciones, grupos definidos, hoy se ha convertido en horizontal, lo cual por un lado empeora la situación ya que el discurso biopolítico del imperio requiere de un enemigo monstruoso e invisible para generar un estado de guerra continuo. EEUU pregona su estado de excepcionalidad sobre otras naciones para situarse por encima de la ley. También para demostrar que sus políticas son las únicas posibles, frente a un mal indescriptible.

Por otro lado, el bio-poder que necesita de la guerra eterna, se encuentra por fuera de la sociedad modificando las formas de trabajos vigentes, mientras la democracia, en el otro extremo, apela a la consciencia de la multitud. Sólo el migrante que despojado de riquezas materiales debe estar en movimiento hacia los centros ejemplares, sabe y puede producir riqueza intelectual suficiente para lograr des-estabilización política; y es en esa posición, que el sistema lo califica como "indeseable" pero lo somete a explotación. Los intelectuales marxianos sostenían que los pobres preocupan a las clases altas simplemente porque les recuerdan su propio destino si no cuidan su riqueza o la dilapidan, pero también porque representan la reserva del aparato industrial. No obstante, Hardt y Negri dicen que el pobre desafía al estatus-quo por su riqueza intelectual cuyas ideas se hacen peligrosas. Los pobres y los migrantes son la base social de la multitud y la materia prima de la verdadera democracia.

Las formas fordistas productivas se han virtualizado acorde a dos elementos importantes, punto en el cual los autores coinciden con Harvey. El primero es la producción simbólica (que hace al trabajo inmaterial) y abstracta donde prima el conocimiento, pero también en los afectos los cuales disponen estados mentales y corporales acorde al funcionamiento del capital. Lo que hoy subyacen en los procesos comunicativos, periodismo y medios en general, no solo es la producción informativa (como nunca antes), sino una disposición afectiva en el receptor de esas noticias. Las guerras en el pasado eran lo suficientemente monstruosas para ser evitadas por todos los medios, y si no quedaba otra alternativa, los involucrados buscaban una rápida victoria para terminar el conflicto. En la era de la bio política la guerra no solo genera pocas bajas entre las tropas imperiales, sino que además se extiende sin límites a todo el planeta. ¿Si no hay suficiente sufrimiento cual es el aliciente para concluir una guerra?. La guerra moderna no genera muerte, escriben Hardt y Negro, sino formas disciplinarias de vida.

Si los organismos internacionales protectores del crédito han generando una gran dependencia del sur global respecto a los grandes centros del capital, ello se debe al rol que juega la corrupción en ese proceso. Eso no significa que los gobiernos locales hayan llevado a sus respectivas naciones a la quiebra por beneficio personal, como la mayoría argumenta, sino que la corrupción es la pieza fundamental para hacer del antiguo estado nacional una red acoplado a otras naciones. Cuando un ejército arriba a un país libre en nombre de la democracia, se da una fase de transición en donde las instituciones precedentes deben dar nacimiento a nuevas formas. Gracias a la corrupción, esa transición se entrega a la hegemonía del capital y pasa a jugar un papel específico en el sistema. La intervención militar sólo se promueve cuando las fallas amenazan el funcionamiento del sistema global, pero esas intervenciones raramente suceden en aquellos países considerados clave para la estabilidad del modelo, sino en las zonas periféricas.

A diferencia de Harvey quien enfatiza en el declive de las naciones, Hardt y Negri 
advierten entonces que el estado nacional y su andamiaje legal son cada vez más fuertes para poder regular el comercio intencional, mecanismo por el cual el capital globalizado puede reproducirse. No obstante, existe un doble peligro en utilizar la "fuerza militar estatal" para la seguridad económica. Por un lado, la imposición de la violencia permitiría proteger los beneficios de las aristocracias globales respecto a los bienes que se comercializan pero a la vez abre la puerta a la aparición de nacionalismos que atentan contra la estabilidad de una región y el circuito mundial de intercambio. Para poder resolver este dilema, el riesgo se transforma en la base angular de toda interacción social en donde el orden vigente no solo queda garantizado por la intervención de un gobierno fuerte, sino además instala una nueva narrativa asociada a la idea que el mundo es un lugar cada vez más peligroso que debe ser regulado e intervenido por los ejércitos. El riesgo moviliza capital y mercancías, por medio de los seguros, pero además legitima la autoridad vigente de una forma silenciosa. Por último pero no por eso menos importante, si en Harvey la posmodernidad es el resultado de políticas económicas y del embargo petrolero del 70, para Hardt y Negri, la posmodernidad es consecuencia (en la misma década) de la revolución cubana y China en donde queda manifiesto el papel de la guerrilla campesina en la forma de hacer política. Hasta esos dos hitos, las revoluciones eran conjuras o resistencias perpetradas por campesinos que no adoptaban una forma urbana de vida. La revolución cubana no solo enseña como el poder militar puede hacerse del poder y transformarse en cuerpo político, sino también como hordas enteras de campesinos se instala en las grandes ciudades amalgamándose con el paisaje de la ciudad. Este todo uniforme hace difícil distinguir al enemigo clásico como décadas atrás.

Sin lugar a dudas, este trabajo se presenta como una obra de inmensurable calidad académica que invita al lector a visitar los límites del imperio mismo. Un trabajo que narrado de forma simple y clara complementa las contribuciones hechas en otra magistral obra, Imperio. Sin lugar a dudas, la guerra preventiva encabezada por Estados Unidos representa el fin de la República. Empero, la democracia, en este abordaje, no es funcional al capitalismo. Si pensamos a la democracia en forma jerárquica (delineada desde arriba hacia abajo) obviamente encontraremos muchos problemas para explicar la conducta de los países que hasta hace décadas atrás se proclamaban ser el centro democrático por excelencia. La intervención militar en Oriente medio ejemplifica, por el contrario, un quiebre en la forma de comprender la democracia que alimenta la idea de un gobierno de "todos por todos" en el sentido helénico clásico, y en consecuencia, los cambios de paradigma producidos por "el Imperio" coadyuvan en su propia desaparición. 


\section{Referencias}

Castoriadis, C. (2006). Lo que Hace a Grecia. De Homero a Heráclito. Seminarios 19821983. Buenos Aires, FCE.

Hardt, M. \& Negri, T. (2004). Multitud. Guerra y Democracia en la era del Imperio. Barcelona, Debate.

Kelsen, H. (1994). Teoría General de las Normas. México, Trillas Ed

Kelsen, H. (2006). Una Nueva Ciencia de la Política?. Buenos Aires, Katz Editores.

Dworking R. (1996). Freedom's Law. The Moral reading of the American Constitution. Cambridge, Harvard University Press.

Harvey, P. (2004). La Condición de la Posmodernidad: investigación sobre los orígenes del cambio cultural. Buenos Aires, Amorrortu Editores.

Minda, G. 1995. Postmodern Legal Movements. Law and Jurisprudence at Century's end. New York, New York University Press.

Schmitt, C. (1990). Sobre el Parlamentarismo. Madrid, Tecnos.

Sunstein, C. (1996). "Legal Reasoning, political Conflict". Oxford, Oxford University Press.

Sunstein, C. (1997). The Partial Constitution. Massachusetts, Harvard University Press. 